\title{
THE RIGHT ATRIAL PULSE IN CONGESTIVE HEART FAILURE
}

\author{
BY \\ PAUL KORNER* AND JOHN SHILLINGFORD $\dagger$ \\ From the Department of Medicine, Postgraduate Medical School, Hammersmith, London \\ Received July 8, 1954
}

In the course of a study of tricuspid incompetence (Müller and Shillingford, 1954) it was found that a high mean venous pressure in chronic congestive heart failure was frequently associated with an abnormal right atrial pressure curve. We have therefore analysed the right atrial pressure records in 48 patients with and without a raised venous pressure. The purpose of this paper is to show a progressive change in the form of the right atrial pulse as the mean venous pressure rises in patients with cardiac failure.

Methods. Forty-eight patients are reported; cardiac disease was present in 44, being rheumatic in 24 , hypertensive in 7 , thyrotoxic in 4 , pulmonary in 3 , and of various types in 6 cases: there was no heart disease in the remaining 4 who were catheterized on account of hepatic disease. There was sinus rhythm in 31 , auricular fibrillation in 16 and auricular tachycardia with $4: 1$ block in one. Intracardiac pressure recordings were made by a Statham strain gauge amplified by a direct current amplifier connected to the Elmqvist electrocardiograph. All pressures were measured from a reference plane $5 \mathrm{~cm}$. below the sternal angle.

\section{RESULTS}

The normal right atrial pressure curve (Bloomfield et al., 1946; and Lagerlöf and Werkö, 1948) shows a positive wave "a" beginning just before, and reaching its peak with, atrial systole; the first part of the wave is due to passive filling of the right atrium and later to atrial contraction. Following this a negative wave $(\mathrm{X})$ occurs at the time of atrial diastole and descent of the base of the heart; towards the end of systole a new positive wave " $v$ " appears due to passive filling of the atrium and continues until the opening of the tricuspid valve. At this point the curve dips to the $Y$ descent before ascending to the a wave of the next cycle. In auricular fibrillation, where the venous pressure is not raised, the curve is the same except for the absence of the $a$ wave and often the fusing of the $X$ and $Y$ descents (Fig. 1). In most cases the $X$ is lower than the $Y$ descent.

In our patients with a raised venous pressure a change in the form of the atrial pulse took place; impairment of the $X$ descent occurred at a mean atrial pressure of approximately $5 \mathrm{~mm}$. $\mathrm{Hg}$ and as the pressure rose further the descent became less until at a mean atrial pressure of approximately $10 \mathrm{~mm}$. $\mathrm{Hg}$ a positive systolic wave was usually found (Fig. 2).

Although the pressure of the $\mathrm{Y}$ descent also rose with the mean atrial pressure, it did so more slowly than the $X$ descent so that the difference in pressure between the $X$ and $Y$ descents increased. The relationship of the difference between the $X$ and $Y$ descents and the mean right atrial pressure was approximately linear (Fig. 3); Fig. 4 shows the relationship between the Y descent and mean atrial pressure.

The change in the pattern was the same for patients in auricular fibrillation and in sinus rhythm and appeared to be independent of underlying cardiac disease or of heart rate. There was a greater incidence of auricular fibrillation in cases with the highest venous pressure.

* Research done during tenure of an Australian and New Zealand Life Insurance Medical Research Fellowship.

$t$ In receipt of a Grant from the Medical Research Council. 


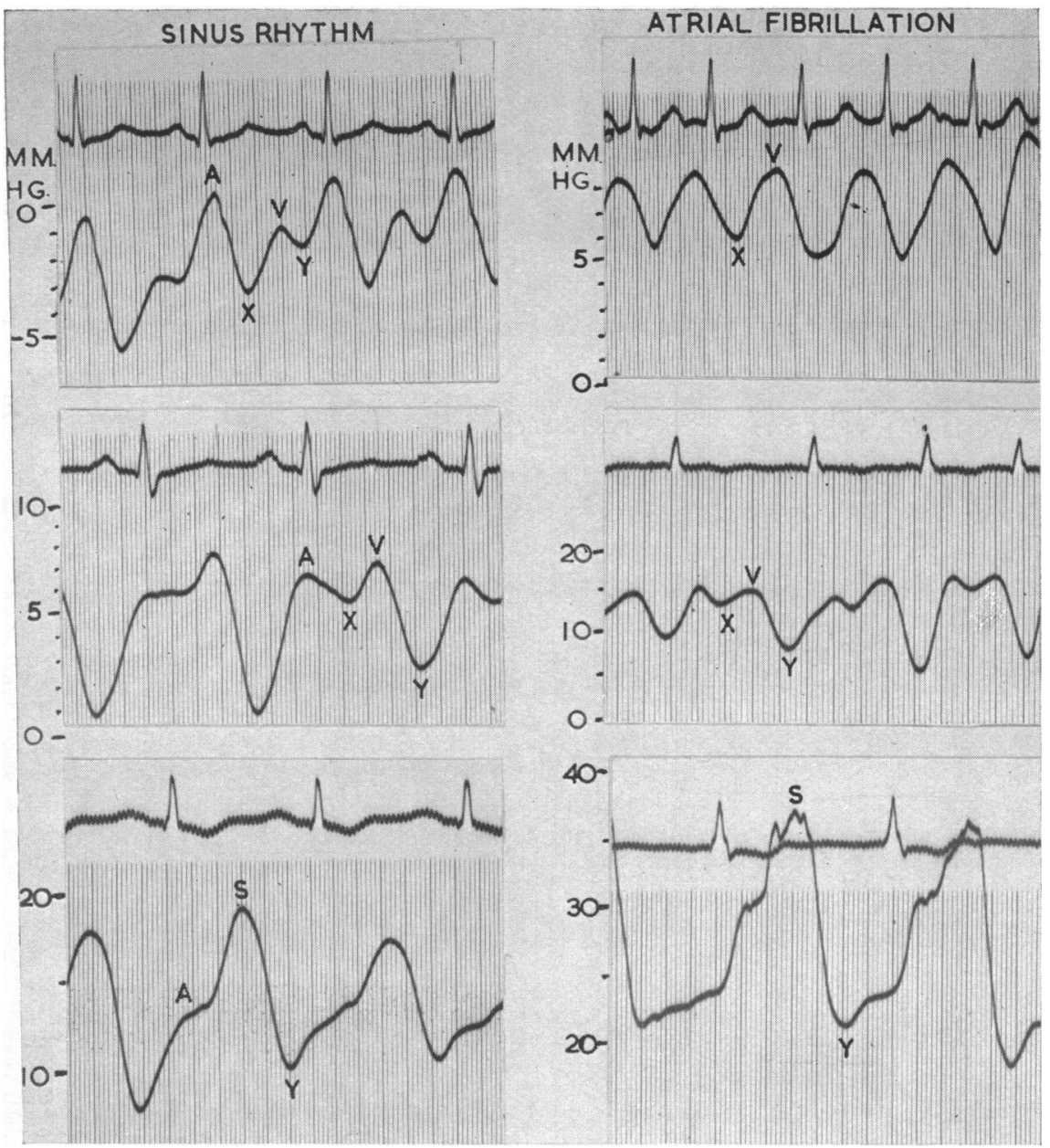

FIG. 1.-Right atrial pressure curves in sinus rhythm and in atrial fibrillation. Top line: normal X descent. Middle line: impaired X descent. Bottom line: $X$ descent replaced by a positive systolic wave.

\section{DisCUSSION}

Although the intrathoracic pressures were not recorded in this study, all the curves were made during quiet respiration when the variations in their shape were minimal. The impaired $X$ descent appears to have a direct relationship to the rise in mean right atrial pressure and it is significant that there is a gradual change of the $\mathrm{X}$ descent into a positive systolic wave; the latter is associated with tricuspid regurgitation and it would seem that an impaired $X$ descent means that a small tricuspid leak is present. These results show the association of a raised venous pressure and tricuspid insufficiency but they do not tell whether the insufficiency is the result of the raised venous pressure in a dilated right heart or whether the raised pressure is due, at least in part, to tricuspid regurgitation. These changes in the pulse contour appear to be related to the mean right atrial pressure and not to the underlying cardiac disease or to the presence of auricular fibrillation. It must be emphasized that these findings were in cases of chronic heart disease; we have recently had the opportunity of studying a patient with severe anæmia, a high cardiac output, and raised venous pressure where a good $\mathrm{X}$ descent occurred and thus does not fall into the pattern shown by the chronic cases. 




ONORMAL SYSTOLIC X DESCENT.

DIMPAIRED SYSTOLIC X DESCENT. POSITIVE SYSTOLIC WAVE.

MEAN RIGHT ATRIAL PRESSURE (MM. HG)

Fig. 2.-The relationship between the mean venous pressure and the form of the atrial pulse.

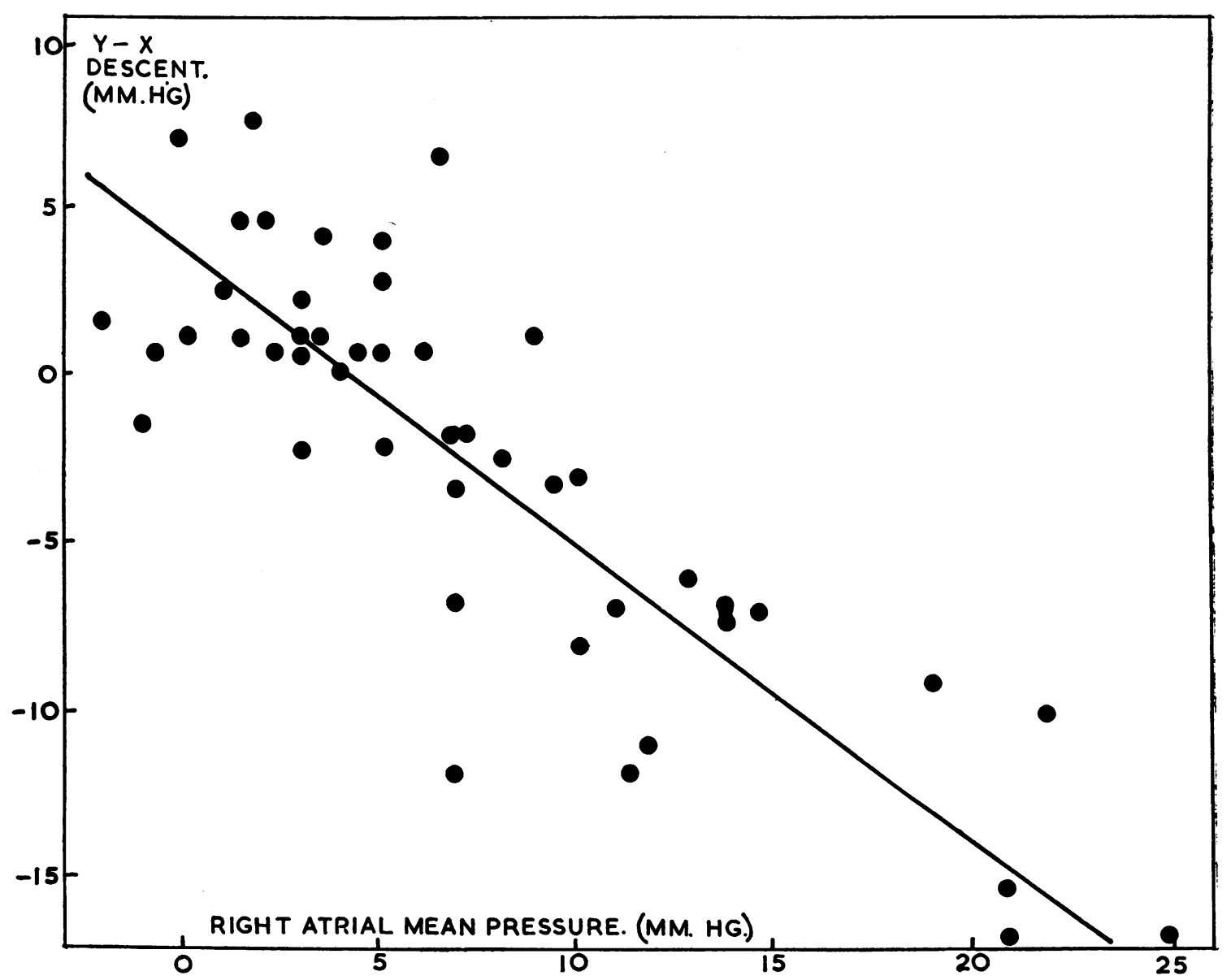

FIG. 3.-The relationship between the right atrial pressure and the difference between the $\mathrm{X}$ and $Y$ descents. $(p=<0.001$. 


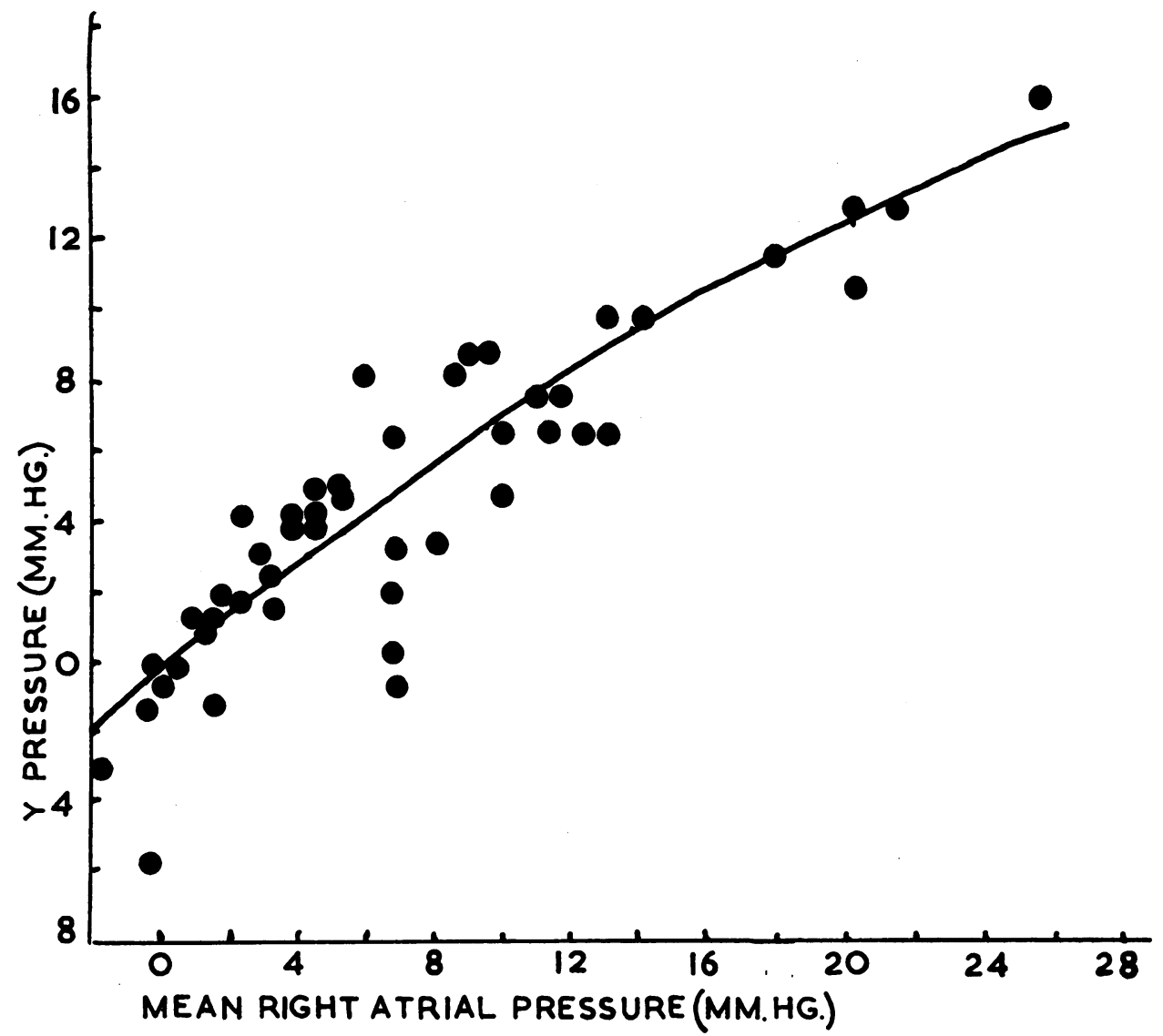

FIG. 4. -The relationship between the mean right atrial pressure and the $Y$ descent. $\quad(p=<0.0001$. $)$

\section{SUMMARY}

The right atrial pressure curves have been studied in 48 patients with and without cardiac failure.

There was a progressive change in the form of the right atrial pulse curve with a rise in the mean right atrial pressure; with moderate rises of venous pressure there was impairment of the $\mathrm{X}$ descent and in the presence of greater mean pressures a positive systolic wave was found.

These changes were not altered by the underlying heart disease or the presence of auricular fibrillation.

The possible relationship of these changes to functional tricuspid incompetence is discussed.

We should like to thank Professor McMichael for his continued help and advice, and also the Physicians of Hammersmith Hospital for their assistance and co-operation.

\section{REFERENCES}

Bloomfield, R. A., Lauson, H. D., Cournand, A., Breed, E. S., and Richards, D. W. (1946). J. clin. Invest., $25,639$. Lagerlöf, H., and Werkö, I. (1948). Cardiologica, 13, 17.

Müller, O., and Shillingford, J. (1954). Brit. Heart J., 16, 195. 